\title{
Spontaneous Esophageal Perforation: Unusual Presentation of Tuberculosis
}

Esophageal tuberculosis is a rare condition, and few cases have been reported in the literature. It is secondary to tuberculous infection of other organs. Progressive dysphagia or odynophagia, or both, are the common presenting symptoms. Neither radiography nor laboratory findings are diagnostic. Upper gastrointestinal endoscopy and biopsy have been reported to be the most useful methods of diagnosing the condition. We report here a case of spontaneous esophageal perforation, most probably secondary to a ruptured tuberculous mediastinal abscess.

A 26-year-old woman with dysphagia was referred from a private clinic to our hospital due to a mid-esophageal perforation, detected on a barium swallow carried out the same day (Figure 1). She had been suffering dysphagia for one week, and fever for two days prior to presentation. There was no associated cough, weight loss, or any other systemic symptom; nor was there any history of upper gastrointestinal instrumentation. No abnormalities were detected on physical examination, apart from fever of $38.5^{\circ} \mathrm{C}$. Her chest radiograph was normal. Esophagoscopy demonstrated a perforation in the mid-esophagus, $25 \mathrm{~cm}$ from the incisors (Figure 2). Brush cytology was carried out, and biopsies were taken from the perforated areas. A nasogastric tube was inserted endoscopically, and the patient was started on nasogastric feeding. Her Mantoux test was $20 \mathrm{~mm}$, and the erythrocyte sedimentation rate (ESR) was $78 \mathrm{~mm}$ in the first hour. A CT of the chest showed an abscess cavity in the subcranial region, filled with barium. No acid-fast bacillus (AFB) was isolated from the direct smear, and the histology showed nonspecific chronic granulation tissue. The patient was started on antituberculosis treatment (rifampicin, isoniazid and ethambutol through a nasogastric tube). The culture for AFB was negative after eight weeks. The patient showed

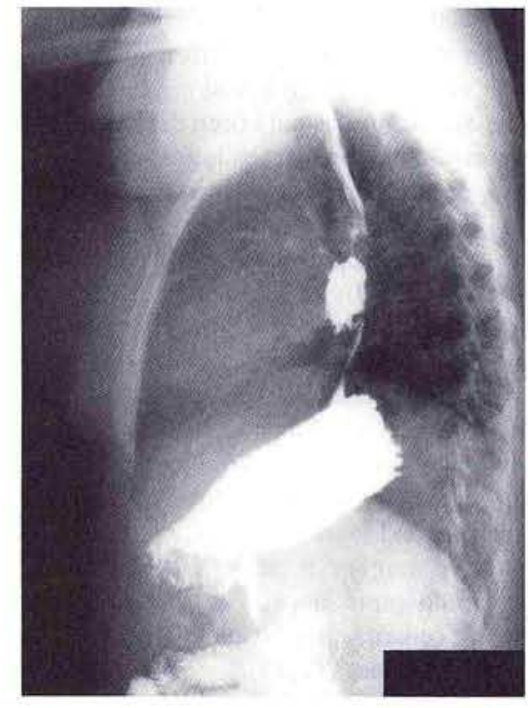

Figure 1: Esophagogram, showing midesophageal perforation.

substantial improvement with treatment, and was asymptomatic within two weeks. A follow-up esophagoscopy (Figure 3) and iohexol swallow after four weeks showed complete closure of the esophageal wall, and the ESR decreased to $23 \mathrm{~mm}$. The patient was able to resume a normal oral diet. After six months of followup, she was well and in a good general state of health.

Tuberculosis is capable of mimicking many diseases, and can affect any anatomical structure. Esophageal tuberculosis is a rare 


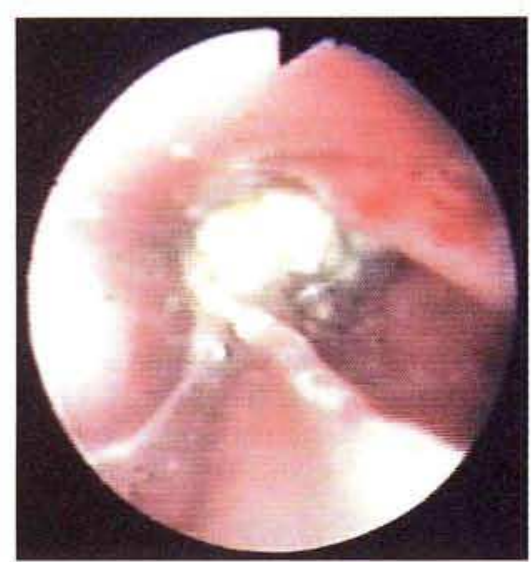

Figure 2: Esophagoscopy, showing mid-esophageal perforation, with a barium residue.

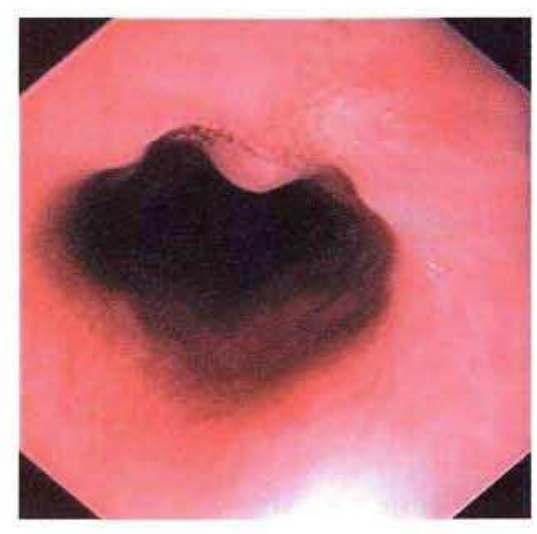

Figure 3: Follow-up esophagoscopy after one month of treatment, showing closure of the esophageal wall.

clinical entity $(1-4)$. It is usually due to the spread of mediastinal tuberculosis, and less often to swallowing of infected sputum, hematogenic dissemination, or lymphogenic infections. Isolated or primary tuberculosis of the esophagus has only been described in a few cases $(5-7)$. The most common presenting symptom is dysphagia or odynophagia, or both, and hematemesis is the least common $(1,8)$. Various diagnostic modalities, such as chest radiography, CT scanning, barium esophagography, or endoscopy and biopsy have been tried $(1,8-10)$. A chest radiograph may show a mediastinal mass or an apical lesion suggesting present or past tuberculosis. It is common to observe mediastinal lymphadenopathy in patients with pulmonary tuberculosis, but this is rarely associated with dysphagia. A rare finding on a chest radiograph is mediastinal abscess. Fiberoptic endoscopy and biopsy are the diagnostic procedures of choice in esophageal tuberculosis, but only a few cases have been reported in the literature, with variable AFB findings and either caseating or noncaseating granuloma findings $(9,11)$. Culture of endoscopic biopsies has been strongly recommended as a routine procedure, since histology occasionally only reveals nonspecific inflammations $(12,13)$.
To our knowledge this is the first report of spontaneous esophageal perforation secondary to tuberculous mediastinal abscess. Other causes of spontaneous esophageal perforation were excluded, and the patient showed a remarkable response to antituberculosis therapy and conservative management.

\section{Z. Ghandour, M. A. Al Karawi, A. E. Mohamed}

Dept. of Gastroenterology, Armed Forces Hospital, Riyadh, Saudi Arabia

\section{References}

1. Rosairo MT, Raso CL, Comer GM. Esophageal tuberculosis. Dig Dis Sci 1989; $34: 1281-4$.

2. Kesztele V. Oesophagustuberkulose. Wien Med Wochenschr 1963; 13: 794-8.

3. Carr DT. Tuberculosis in a carcinoma of the esophagus. Am Rev Respir Dis 1942; 46: 346.

4. Al Karawi MA, Mohamed AE, Yasawy MI, Graham DY, Shariq S, Ahmed AM, et al. Protean manifestation of gastrointestinal tuberculosis: report on 130 patients. J Clin Gastroenterol 1995; 20: 225-32.

5. Seivewright N, Feehally J, Wicks ACB. Primary tuberculosis of the esophagus. Am J Gastroenterol 1984; 79: 842-3.

6. Dow CJ. Esophageal tuberculosis: four cases. Gut 1981; 22: 234-6.

7. Zipprich B, Heine R, Gerlach HF. Esophageal ulcer caused by atypical microbacteria: a case report. Endoscopy 1993; 25: $482-3$.

8. Newman RM, Fleshner PR, Lajam FE, et al. Esophageal tuberculosis: a rare presentation with hematemesis. Am J Gastroenterol 1991; 86: 751-5.

9. Gordon AH, Marshall JB. Esophageal tuberculosis: definitive diagnosis by endoscopy. Am J Gastroenterol 1990; 85: 174-7.

10. Schneider R. Tuberculous esophagitis. Gastrointest Radiol $1976 ; 1: 143-5$.

11. Gupta SP, Arora A, Bhargava DK. An unusual presentation of esophageal tuberculosis. Tuber Lung Dis 1992; 73: 174-6.

12. Shah I. Tuberculosis of the esophagus and the importance of bacteriological tissue cultures. Endoscopy $1986 ; 18: 254-5$.

13. Al Karawi MA. Dysphagia in patients with mediastinal tuberculous lymphadenitis: three case reports. Saudi Med J $1984 ; 5 ; 397-400$.

Corresponding Author

Z. Ghandour, M.D.

Dept. of Gastroenterology

Armed Forces Hospital

P.O. Box 7897

Riyadh 11159

Saudi Arabia

Fax: $+966-1-4786088$ 